\title{
The Mutual Influence of Signals from the Location Monitoring Equipment and Technological Communication in the High- Frequency Path of Power Transmission Line
}

\author{
Renat Minullin ${ }^{1 *}$, Ilshat Fardiev ${ }^{2}$ \\ ${ }^{I}$ Kazan State Power Engineering University, Krasnosel'skaja 51 St., Kazan, 420066, Tatarstan Republic, Russia \\ 2JSC "Grid Company", Bondarenko St., 3, Kazan, 420094, Russia \\ *Corresponding author E-mail: minullin.r1@mail.ru
}

\begin{abstract}
The paper describes the main characteristics of equipment used for technological communication by means of overhead electric transmission lines: high-frequency relay protection, command transmission of emergency control, high-frequency communication for the transmission of telemechanics and telephony signals, as well as equipment for a location equipment for monitoring the condition of electric transmission lines. The results of experimental studies on the mutual influence of the signals from the location monitoring equipment and technological communication in the high-frequency path of overhead transmission lines are presented. It shows a lack of effect of signals from location monitoring equipment on the work of technological communication equipment. Methods are proposed to reduce the influence of technological communication signals on the operation of location equipment: the method of signal accumulation and the method of digital filtering of signals. Analysis of the results of joint operation of the location monitoring equipment and high-frequency communication equipment under various conditions and operating modes on operating 35-330 kV overhead lines confirms their full compatibility.
\end{abstract}

Keywords: electric transmission line; High-frequency path; Equipment for location monitoring; Equipment for technological communication; Mutual influence.

\section{Introduction}

High-voltage transmission lines with a voltage of $35 \mathrm{kV}$ and above are widely used to transfer technological information necessary for the management and operation of power systems.

At the same time, relay protection signals, emergency control automatics and high-frequency communication with the transmission of telemechanics and telephony signals are transmitted [1-3] Simultaneously, high-frequency paths of power lines are used to monitor power line wires in order to detect damage on them in the form of breaks and short circuits, as well as the detection of ice formations [4-10].

The mentioned equipment of technological communication works in the frequency range of $16-1000 \mathrm{kHz}$, which is allowed for use by power engineers for industrial purposes. The transmission of technological communication signals is carried out in the pass band of $3.4 \mathrm{kHz}$. Transmitter power can reach $80 \mathrm{~W}$, which corresponds to an output signal amplitude of approximately $80 \mathrm{~V}$ at a load of $75 \mathrm{Ohm}$. The sensitivity of the receivers is approximately $40 \mathrm{dBm}$. The duration of the signal transmission is in the range of 10-25 ms [11-12].

Let us consider brief characteristics of the equipment used for technological high-frequency communication.

\section{Characteristics of the Equipment of Tech- nological Communication}

With high-frequency relay protection, two types of protection are mainly used:

- remote with high-frequency blocking;

- differential-phase.

The signals of the high-frequency relay protection are the sending of one frequency, i.e. the communication channel is singlefrequency.

The action of differential-phase protection is based on comparing the phases of the currents along the ends of the protected line.

Transmission of the phase of the current of this end to the opposite end of the line is carried out on the high-frequency channel by the method of amplitude manipulation of the carrier frequency of the transmitter in the range 16-1000 Hz. Manipulation is carried out with a voltage of an industrial frequency of $50 \mathrm{~Hz}$, proportional to the short-circuit current. The pulses of the carrier frequency are transmitted during certain half-periods (positive or negative) of this voltage and for a duration of $10 \mathrm{~ms}$. The optimum bandwidth of the receiver for relay protection channels is $1200-1400 \mathrm{~Hz}$.

The equipment for transmitting the commands of the emergency control system is single-frequency. The transmission of commands is usually carried out by a single-pulse frequency code (each command corresponds to a signal of a certain frequency within a $3.5 \mathrm{kHz}$ band), but can also be formed by a twofrequency parallel or sequential code. The carrier frequencies are 
in the range $16-1000 \mathrm{~Hz}$ with a bandwidth of $3.5 \mathrm{kHz}$. Up to 32 (64) teams can be transferred. The command transmission time is $25 \mathrm{~ms}$, the accuracy of the start and end of the command is $1 \mathrm{~ms}$. High-frequency communication equipment for the transmission of telemechanics and telephony signals is intended for the organization of operational dispatch and technological control channels, telemechanics, data transmission in the electric power industry. For carrier transmission, a frequency range of 20 to $1000 \mathrm{kHz}$ is used with a bandwidth of 0.3 to $3.4 \mathrm{kHz}$, a modulation type of TDMA. Voice information is transmitted in the frequency band $0.3-3.3 \mathrm{kHz}$. The telemechanics channels have passages of $150 \mathrm{~Hz}$ with a pulse duration of $10 \mathrm{~ms}$ and during transmission occupy a frequency band in the range $2.3-3.4 \mathrm{kHz}$.

The equipment of the location complex generates probing pulses of a rectangular or triangular shape with a duration of $1-10 \mu$ s with an amplitude of $20-50 \mathrm{~V}$ in a transmission band of $1000 \mathrm{kHz}$. [1-9] The amplitudes of the signals of the pulsed location complexes and the equipment of the high-frequency technological communication are approximately the same, their maximum values can reach $100 \mathrm{~V}$. The duration of the signals is very different. The durations of the pulses of the location complex are in the range 1$10 \mu \mathrm{s}$. It is $1000-10,000$ times less than the duration of the signals of the technological communication equipment, which is within 10-25 $\mu$ s. In this case, pulse signals use a bandwidth of $1000 \mathrm{kHz}$, and high-frequency signals $-4 \mathrm{kHz}$.

Thus, the signal voltage per unit bandwidth in $1 \mathrm{~Hz}$ is $1 \times 10^{-10} \mathrm{~V} /$ $\mathrm{Hz}$ for the location complex, and for the high-frequency communication equipment it is $1 \times 10^{-4} \mathrm{~V} / \mathrm{Hz}$.

\section{Results of Experimental Studies}

In other words, in the $4 \mathrm{kHz}$ frequency band used by the highfrequency apparatus, the signal energy of the location complex equipment is six orders of magnitude (a million times) lower than the signal energy of the high-frequency communication equipment. Naturally, localized pulses with such low energy cannot cause significant distortion of the signals of the high-frequency communication equipment, which can lead to their false triggering. As calculations and experiments have shown, the pulsed signals of the location complex, due to their small power, do not affect the operation of high-frequency equipment of technological communication, which maintains relay protection systems, telemechanics, emergency automatics and telephony.

Studies on local monitoring of power transmission lines have been conducted by theoretical and experimental methods by the staff of Kazan State Power Engineering University under the guidance of professor Renat Minullin for 23 years, since 1995. Regular measurements on existing power lines began in 2007 at the substations Bugulma-110 and Kutlu Bukash (Tatarstan Republic), and in 2013 measurements began at the substations Shkapovo (Bashkortostan Republic) and Baksan (North Caucasus). Locating systems are working properly and reliably to this day, servicing power lines with a voltage of $35-330 \mathrm{kV}$, over which over 500 thousand reflectograms were taken during the elapsed time.

The problem of mutual electromagnetic compatibility of the location complex with high-frequency equipment for technological communication was studied in detail in 2007-2009 by theoretical means and was accompanied by measurements on existing power transmission lines, including power lines departing from the Bugulma-500 substation. This problem was successfully solved by a group of Kazan State Power Engineering employees under the guidance of Professor Renat Minullin 10 years ago in 2007-2009. For 10 years of experiments on existing $35-330 \mathrm{kV}$ lines and engineering solutions, there has never been a situation where signals from location complexes interfered with the operation of high-frequency equipment for technological communication. During the entire operation of these transmission lines, there were no comments from the services of relay protection, emergency control and communications.
Below are the results of experimental studies performed in 20072009 by the Kazan State Power Engineering University staff [13$15]$.

Let us consider, as examples, the results obtained on operating power lines and clearly characterize the signals of the location complex and high-frequency technological communication equipment. Technological communication is carried out over highfrequency paths of power lines, which includes a high-frequency cable (HC), a connection filter (CF) with a high-voltage coupling capacitor (CC) and a high-frequency choke (HFC).

Example 1. In high-frequency channels, the amplitude of the signals of the high-frequency equipment is always higher than the location pulses, as can be seen in Figure 1.

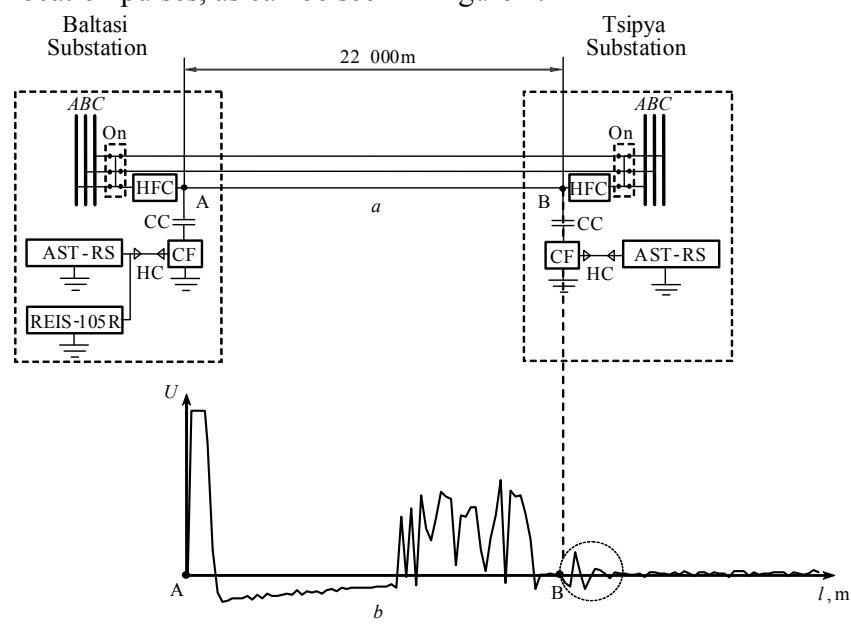

Fig. 1: Comparison of a random discrete packet of fluctuation jamming and a localized pulse on a $35 \mathrm{kV}$ line with a length of $22000 \mathrm{~m}: a$ - line diagram; $b$ - a trace of the line with interference from the RF equipment and a local impulse reflected from the OT at the end of the line at point B (indicated by an oval)

In this case, the location pulses from the REIS-105R reflectometer $2 \mu \mathrm{s}$ long are much smaller than the pulses of the AST-RS equipment and cannot affect the operation of this apparatus.

Example 2. In Figure 2 shows a reflectogram taken at the operating line "Bugulma-500-Pismyanka" with a voltage of $220 \mathrm{kV}$, where the equipment for the relay protection of the high-frequency blocking (HFB) is installed (in Figure 2 it is not indicated). On the reflectogram of Figure 2, $b$, the signal of the high-frequency equipment is visible, against the background of which it is impossible to detect the pulse of the locational complex reflected from the end of the line. The application of averaging of reflectograms makes it possible to isolate the local impulse in point $\mathrm{B}$, as can be seen in Figure 2, $c$.

The presence of a local impulse with a voltage of $22 \mathrm{~V}$ and a duration of $4 \mu \mathrm{s}$ for the operation of the high-frequency blocking does not affect. 


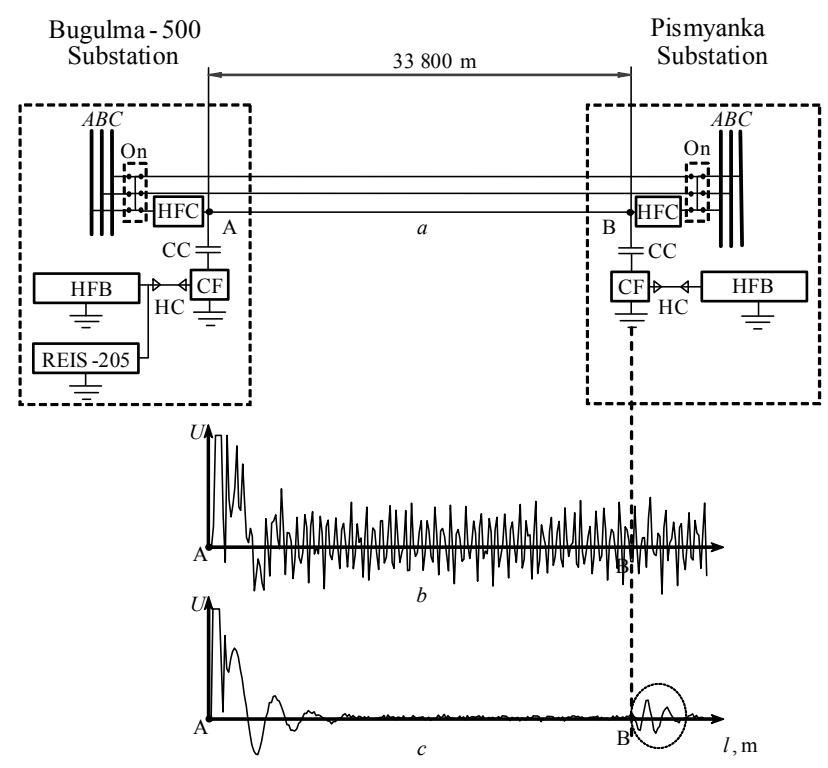

Fig: 2. Selection by the averaging method among random interference from the equipment of the high-frequency pulse of the local sounding on the $220 \mathrm{kV}$ line with a length of $33800 \mathrm{~m}$ : $a$-circuitline; $b$ - reflectogram of the set of signals of the equipment HFB and REIS-205; c - averaged trace of 15 measurements with a dedicated location pulse reflected from the OT at the end of the line at point B (indicated by an oval)

Example 3. The measurements were carried out on an air line of $220 \mathrm{kV}$ "Bugulma-Pismyanka" with a length of $33.8 \mathrm{~km}$ without ice. On the line there is a channel for relay protection of the highfrequency blocking type equipment. The sounding was carried out by the REIS-205 reflectometer, which was connected to the RF cable as can be seen in Figure 3 .

In the reflectometer, the following pulse parameters were set, the amplitude: $\mathrm{U}=22 \mathrm{~V}, \tau=4 \mu$ s, averaging 10 .

As the measurements have shown, the location signals do not affect the operation of the relay protection equipment regardless of the time reflectogram registration.

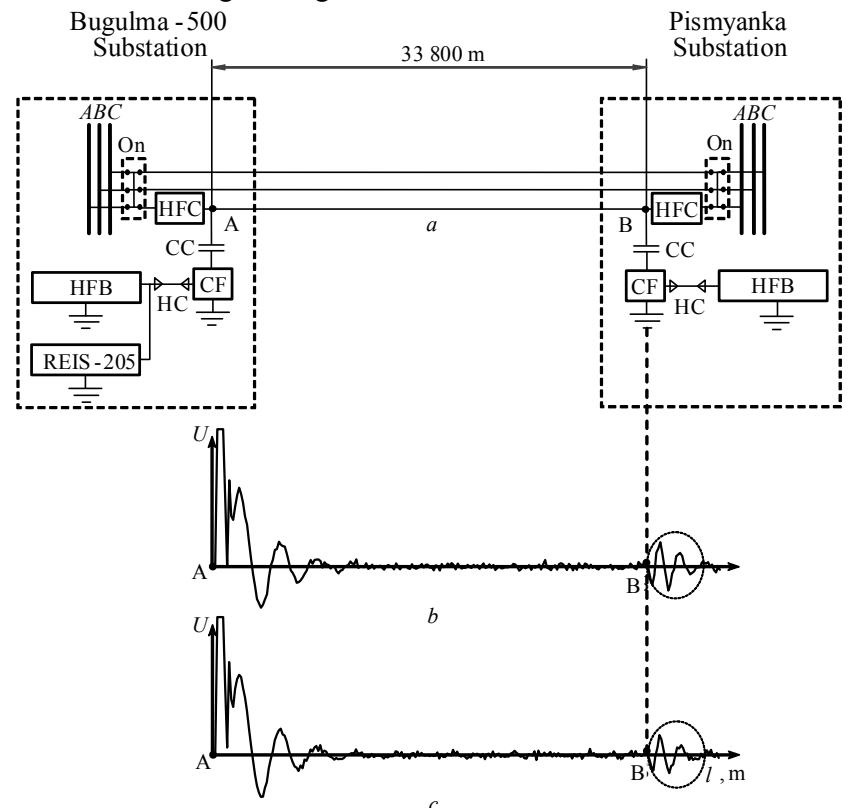

Fig. 3: Selection by averaging method among the interference from the equipment of the high-frequency sounding signals of the local sounding reflected from the HFC at the end of the $220 \mathrm{kV}$ line $33800 \mathrm{~m}$ at point $\mathrm{B}$ (indicated by an oval) on different probing days: $a$ - line diagram; $b$ - the reflectogram registered on January 28, 2008; $c$ - a reflectogram registered on February 15, 2008

Example 4. In Figure 4 shows the reflectograms taken at the current power transmission line "Bugulma-500-Bugulma 110" with a voltage of $110 \mathrm{kV}$, where the high-frequency blocking equipment was installed. On the reflectograms of Figures $4, b$ and 4, $c$ there are cases of recording signals of the location complex in the absence and in the presence of ice on the wires of the current transmission line. The connection of the location complex does not affect the operation of the high-frequency blocking equipment.

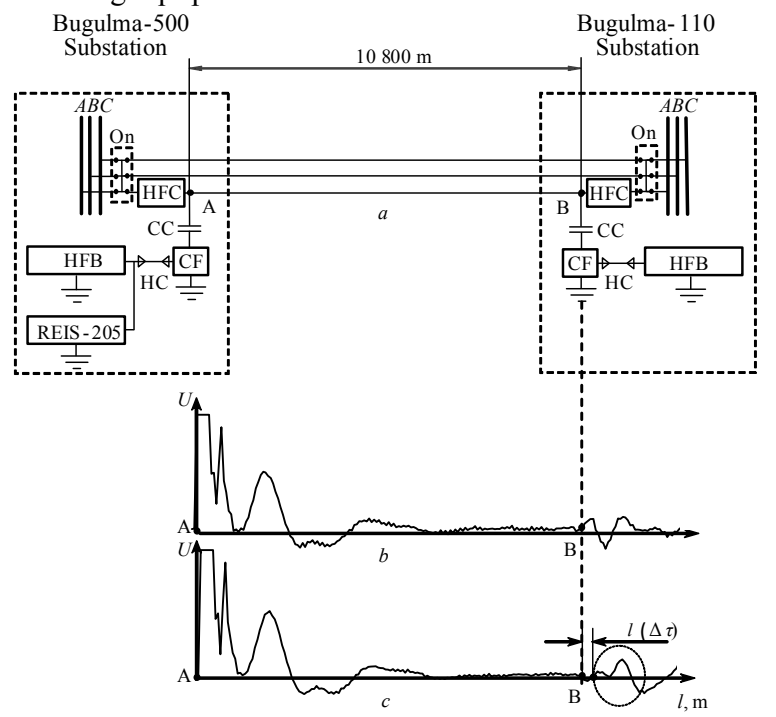

Fig. 4: Detection of ice on the $110 \mathrm{kV}$ line $10,800 \mathrm{~m}$ long by the delay of the reflected signal by $\Delta \tau$ (indicated by an oval): $a$ - line diagram; $b$ averaged trace of the line without ice; $c$ - averaged trace of the line with ice

Example 5. Detection of the short-circuit on the wires of the "Rybnaya Sloboda-Kamskaya" power line with a voltage of $110 \mathrm{kV}$ was carried out by means of local sounding with the $\mathrm{ABC}$ high-frequency communication equipment. On the reflectogram of Figure 5, the impulse reflected from the place of a short circuit, because of its smallness, cannot be detected on the background of the signals of the $\mathrm{ABC}$ equipment. It can be detected only by averaging 10 or 30 reflectograms. For the operation of the $\mathrm{ABC}$ equipment, the pulses of the local sounding by the REIS-205 reflectometer with an amplitude of $22 \mathrm{~V}$ and a duration of $3 \mu$ s do not influence.

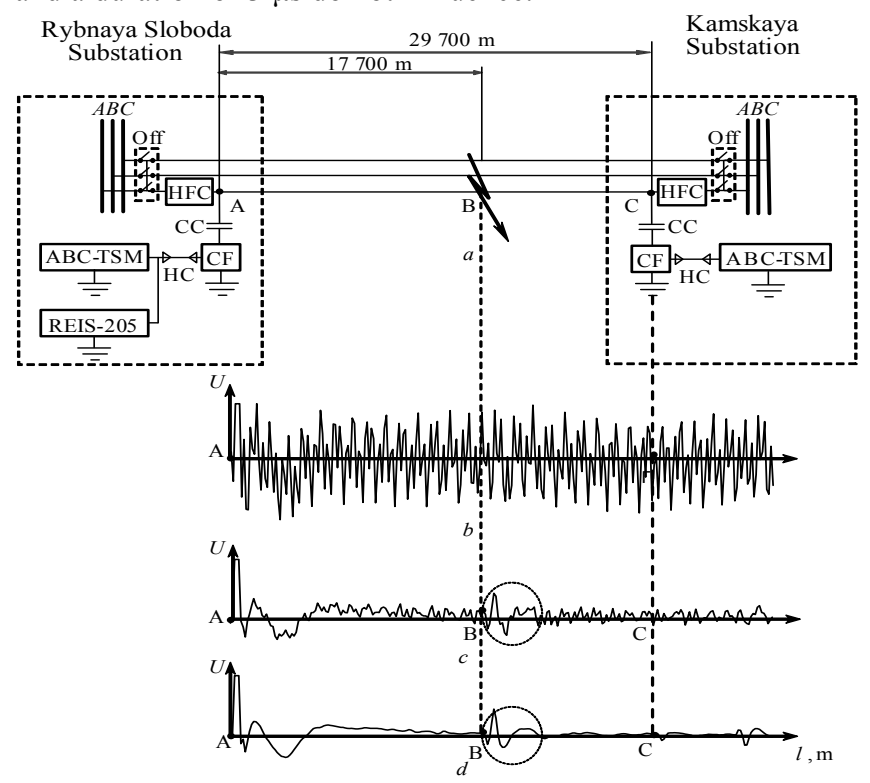

Fig. 5: Selection of a local sounding pulse from the location of a twophase short circuit on the $110 \mathrm{kV}$ line with a length of $29700 \mathrm{~m}$ by the averaging method among random disturbances from the ABC-TSM equipment: $a$ - line diagram; $b$ - reflectogram of the set of signals of the equipment ABC-TSM and REIS-205; $c, d$ - averaged reflectograms with a dedicated pulse reflected from the point of short circuit at point $B$ (indicated by an oval), with averaging of 10 and 30 reflectograms, respectively 
At the same time, the application of the averaging method makes it possible to reliably isolate the pulses of the local sounding among random noise, which are the signals of the technological communication equipment for the location pulses, and thus neutralize their influence on the local measurements.

Example 6. In Figure 6 it is shown an example of the selection on the reflectogram of pulses reflected from the place of a short circuit. Figure $6, b$ shows the reflectogram obtained on the "Rybnaya Sloboda-Kamskaya" transmission line with $110 \mathrm{kV}$ voltage in the presence of transmission line pulses of local sounding from the REIS-205 reflectometer and the signals of the ABC transmitters. Against the background of the signals of the transmitters, the pulses of the local sounding, reflected from the short circuit at a distance of $17,700 \mathrm{~m}$ from the beginning of the line, are practically impossible to detect.

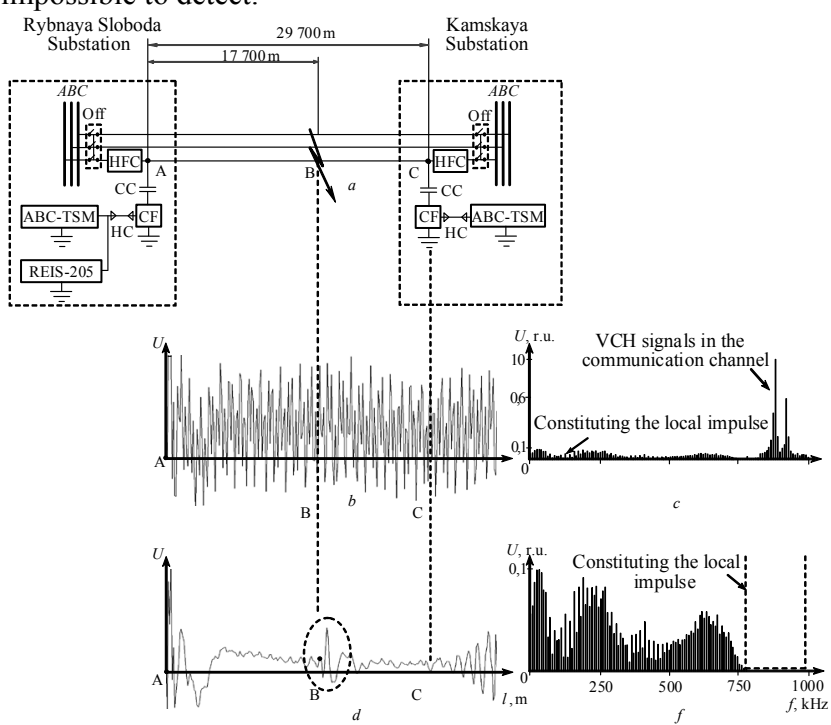

Fig. 6: Selection of the local sounding pulse reflected from the place of a two-phase short circuit on the $110 \mathrm{kV}$ line with a length of $29700 \mathrm{~m}$ among systematic disturbances from the ABS-TSM equipment from the ABS-TSM equipment: $a$ - line layout; $b$ - reflectogram of the set of signals of the equipment ABS-TSM and REIS-205; $c$ - the spectrum of the reflectogram; $d$ - processed and reconstructed reflectogram with a dedicated pulse reflected from place of fault at point B (indicated by an oval); $f$ processed spectrum of the reflectogram after digital filtration

The spectrogram of the set of signals present in the highfrequency path of the power line is shown in Figure 6, in against the background of the components of the spectrum of the probe pulse. The carriers with side components of the signals of the $\mathrm{ABC}$ transmitters operating at frequencies of 894 $\mathrm{kHz}$ and $938 \mathrm{kHz}$ are clearly visible. Figure $6, d$ shows the same spectrogram (with amplification of the spectrum components), but with the "cut out" sections on the frequency axis using digital filters. The boundaries of the cut out sections are indicated in Figure 6, $d$ vertical dashed lines. The cut out sections overlap portions of the spectra with harmonic components of the signals of the $\mathrm{ABC}$ transmitters near the frequencies of 894 and $938 \mathrm{kHz}$. Thus, the signals of the transmitters, which are interference to the local sounding pulses from the spectrum, have been removed.

On the basis of the transformed spectrum of signals, the reflectogram of the local sounding, shown in Figure $6, d$ has been reconstructed. On the reconstructed reflectogram, the signals of the $\mathrm{ABC}$ transmitters are completely absent, and at a distance of $17700 \mathrm{~m}$ at point $\mathrm{B}$ there is clearly a negative pulse reflected from the place of short circuit on the line, with traditional accompanying oscillations with a damped amplitude.

Thus, the influence of the signals of the technological communication equipment (systematic interference for the local channel) on the selection and recognition of localized pulses is neutralized. Experimental studies have shown that signals reflected from line inhomogeneities (short-circuit places of wires) can be reliably identified against the background of technological signals of the high-frequency tract by spectral analysis of current reflectograms.

Let us estimate the influence of local impulses on the operation of the equipment for technological communication.

The ratio of the amplitude of the carrier signal of the transmitter $\mathrm{ABC}$ at $894 \mathrm{kHz}$, located at point $\mathrm{A}$, and the amplitude of the 115 th harmonic of the reflectometer pulse corresponding to this frequency, is $40 / 1$. The ratio of the amplitude of the carrier signal of the transmitter at a frequency of $938 \mathrm{kHz}$, located at the point $\mathrm{A}$, and the amplitude of the 120th harmonic of the reflectometer pulse corresponding to this frequency, is $20 / 1$.

Analyzing these ratio, it can be concluded that the impact of the pulse of the REIS-205 is practically absent, since the energy of the reflectometer pulse entering the receiving channel having a bandwidth of $4 \mathrm{kHz}$ is negligible. This conclusion applies to both receivers of $\mathrm{ABC}$ equipment located at points $\mathrm{A}$ and $\mathrm{C}$.

Thus, the differences in the spectrograms of the broadband probing pulse of the reflectometer and the narrowband signals of the ABC transmitter are clearly visible in Figure 6. These differences can be used, using digital filters, to separate these signals, if they are in the same high-frequency path, which is done during the operation of the location complexes on the operating power lines $35-330 \mathrm{kV}$.

The analysis of the results of joint operation of the monitoring equipment and high-frequency communication equipment under various conditions and operating conditions on $35-330 \mathrm{kV}$ lines confirms their complete electromagnetic compatibility.

\section{Conclusion}

Our location equipment has been successfully operating to date from 2009 on 2 substations "Kutlu Bukash" and "Bugulma-110" (Tatarstan), and also since 2013 at the substations "Shkapovo" (Bashkortostan) and "Baksan" (Northern Caucasus), without interfering with the equipment of high-frequency technological communication [16-19].

Many years of experience in high-voltage transmission lines shows the lack of influence of location complexes on the operation of high-frequency technological communication systems [20-25]. Analysis of the results of joint operation of the monitoring equipment and high-frequency communication equipment under various conditions and operating conditions on $35-330 \mathrm{kV}$ lines confirms their complete electromagnetic compatibility.

\section{Acknowledgement}

The authors are grateful to the employees of the Volga and Bugulma electric grids (JSC "Grid Company", Tatarstan), as well as E.I. Lukin for help in making measurements.

The results of the research have been processed and, with the financial support of the Ministry of Education and Science of the Russian Federation under the Agreement No. 14.574.21.0141 of September 26, 2017, the unique identifier of the RFMEF157417X0141 project.

\section{References}

[1] Mikutskiy GV, Skital'tsev VS (1969), High-frequency communication over power lines. Moscow: Energia.

[2] Ishkin VKh, Tsitver II (1981), High-frequency communication on power lines 330-750 kV. Moscow: Energoizdat.

[3] Shkarin YuP (2001), High-frequency paths of communication channels along power lines. Moscow: NTF "Energoprogress".

[4] Shalyt GM (1982), Determination of fault locations in electrical networks. Moscow: Energoizdat.

[5] Minullin RG (2002), Methods and equipment for locating faults in power networks. Kazan: Information Center "Energoprogress". 
[6] Minullin RG, Zakamsky EV (2001), Determination of damage sites in electrical networks with voltage of $6-35 \mathrm{kV}$ by pulse method. Materials of reports of the Russian National Symposium on Energy. Kazan: Kazan State Power University, 2, 62-64.

[7] Minullin RG, Zakamsky EV, Detection of damages in electrical distribution networks by the location method. Kazan: Information Center "Energoprogress".

[8] Minullin RG, Fardiev ISh (2008), Locational diagnostics of overhead transmission lines. Kazan: Kazan. state. power. University.

[9] Minullin RG, Detection of ice formations on power transmission lines by local sounding. Kazan: Kazan State Power University, 2010.

[10] Minullin RG (2017), Connecting diagnostic locating equipment to overhead power lines. Power 10, 10-14.

[11] Handbook on the design of information transmission systems in the energy sector. Ed. Ishkina V.KH. Moscow: Energoatomizdat, 1991.

[12] Minullin RG (2004), Methods and Means of High-Frequency Communication on Power Lines. Kazan: Information Center "Energoprogress".

[13] Minullin RG, Lukin EI, Sukhomyatkin MO et al (2011), Specifics of detecting ice coatings on electric power lines using radar probing. Russian Electrical Engineering 82(5), 237-242.

[14] Minullin RG, Lukin EI, Shaikhutdinov FT, Khalilov RG (2012), An averaging method for identification of location probing signals in the high-frequency channel of transmission lines. Russian Electrical Engineering 83(1), 30-34.

[15] Minullin RG, Lukin EI, Khakimzyanov EF, Vedernikov SG, Lavrent'ev IS (2011), Recognition of location-probing signals in highfrequency path of power-transmission line using spectral analysis. Russian Electrical Engineering 82(7), 383-387.

[16] Minullin RG, Goryushin YuA, Borshchevsky AI, Kasimov VA, Yarullin MR (2015), Experience of multichannel location monitoring of ice on power transmission lines. Power engineering of $\mathrm{Ta}$ tarstan 2(38), 3-18.

[17] Minullin RG, Goryushin YuA, Borshchevsky AI, Kasimov VA, Yarullin MR (2015), Multichannel location detection system for ice on high-voltage transmission lines. Energy of a single network $5(22), 44-58$

[18] Minullin RG (2015), Multichannel location monitoring of ice on overhead power lines. Electricity. Transmission and distribution 5(32), 76-87.

[19] Minullin RG (2017), Use of location sounding to detect damage to the wires of high-voltage power lines. Electric stations 4, 26-35.

[20] Minullin RG (2017), Locational monitoring of ice-frost deposits and damages on the wires of overhead transmission lines. Moscow: Energetik, Part 1. PP. 1-88, Part 2. PP. 1-76, Part. 3. PP. 1-60.

[21] Minullin RG, Goryushin YuA, Chereshnyuk SV, Kasimov VA Yarullin MR (2015), Multichannel radar monitoring of ice on power lines. Proceedings 16th International Workshop on Atmospheric Icing of Structure (IWAIS-2015). Sweden, Uppsala, 95-97.

[22] Minullin RG, Kasimov VA, Yarullin MR, Analysis of radar equipment indications and weight sensors indications during detecting ice deposits on power lines. Proceedings 16th International Workshop on Atmospheric Icing of Structure (IWAIS-2015). Sweden, Uppsala, 105-107.

[23] Minullin RG, Kasimov VA, Filimonova TK, Borshchevsky AI (2017), Visualization of the results of power transmission lines locational probing. Proceedings 17th International Workshop on Atmospheric Icing of Structure (IWAIS-2017). China, Chongqing, 277-280.

[24] Kasimov VA, Minullin RG (2017), Determining the type of icing and rime sediments on wires of overhead power transmission lines by locational method. Proceedings 17th International Workshop on Atmospheric Icing of Structure (IWAIS-2017). China, Chongqing, $2017,360-364$

[25] Minullin RG, Kasimov VA, Filimonova TK, Gazizullin RM, Minkin AS (2017), Reflectometry method of ice detection on wires of overhead transmission lines. International Journal of Mechanical Engineering and Technology 8(10), 688-698. 